\title{
Automated Detection of Antropogenic Changes in Municipal Infrastructure with Satellite Sub-meter Resolution Imagery
}

\author{
D. K. Mozgovoy ${ }^{1[0000-0003-1632-1565]}$, D. V. Kapulin ${ }^{2[0000-0002-4260-1408]}$, \\ D. N. Svinarenko ${ }^{1[0000-0003-3179-9129]}$, A. I. Sablinskii ${ }^{30000-0001-5356-5628]}$,
T. N. Yamskikh ${ }^{2[0000-0002-5658-6632]}$ and R. Yu. Tsarev \\ ${ }^{1}$ Oles Honchar Dnipro National University, 72, Gagarin Prospect, Dnipro, 49000, Ukraine \\ ${ }^{2}$ Siberian Federal University, 79, Svobodny Prospect, Krasnoyarsk, 660041, Russia \\ ${ }^{3}$ Kemerovo State University, 73, Sovetsky Prospect, Kemerovo, 650043, Russia \\ tsarev.sfuemail.ru
}

\begin{abstract}
This paper discusses an efficient method for the automated detection of antropogenic changes in urban development with multispectral satellite producing sub-meter resolution imagery. The proposed method efficiency is confirmed with vector layers of detected changes in urban development obtained as a result of processing infrared and visible multidate images. The developed technique significantly reduces complexity and thus increases operational efficiency of map updating due to automation of satellite imagery processing.
\end{abstract}

Keywords: Satellite Monitoring, Urban Development, Multidate Images, Image Processing, Map Updating.

\section{Introduction}

The intensive development of new construction technologies in recent decades has been one of the main reasons for the rapid dynamics of urban development worldwide. This trend is observed both in the high-rise and low-rise housing and in the construction of industrial and commercial facilities. Therefore, in the field of information technologies there is an urgent task to develop highly efficient methods for automated detection of changes in urban development. This can be judged from the numerous scientific publications of recent years in the field of applied use of aerospace images [1-5].

Ground-based measurements and aerial imagery have traditionally been used to regularly update urban spatial databases. At the same time, the periodicity of updating urban maps was extremely low (usually once every few years) due to high complexity of data collection and processing. In recent years significant progress in the development of optoelectronic multispectral scanners (Table 1) has fostered the use of satellite imagery for assessing the evolution of land-based objects and updating urban maps [6-8]. Their use is especially effective for the automated detection of changes in 
various anthropogenic objects, such as buildings, roads, engineering structures, etc. [9-13].

Table 1. Satellites with multispectral scanners of sub-meter resolution.

\begin{tabular}{|c|c|c|c|c|c|c|c|}
\hline \multirow[b]{2}{*}{ Satellite } & \multirow{2}{*}{$\begin{array}{l}\text { Year of } \\
\text { Launch }\end{array}$} & \multirow{2}{*}{$\begin{array}{l}\text { Operator } \\
\text { (country) }\end{array}$} & \multicolumn{3}{|c|}{ Resolution } & \multirow{2}{*}{$\begin{array}{l}\text { Swath, } \\
\text { km }\end{array}$} & \multirow{2}{*}{$\begin{array}{c}\text { Accuracy of } \\
\text { geolocation, } \\
\mathrm{m}\end{array}$} \\
\hline & & & $\begin{array}{c}\text { PAN/MS, } \\
\mathrm{m}\end{array}$ & $\begin{array}{c}\text { Radiometric, } \\
\text { bit }\end{array}$ & $\begin{array}{l}\text { No. of } \\
\text { bands }\end{array}$ & & \\
\hline EROS-B & 2006 & Israel & 0,7 & 10 & 1 & 7 & N/A \\
\hline Cartosat-2 & 2007 & India & 0,8 & 10 & 1 & 9,6 & N/A \\
\hline WorldView-1 & 2007 & USA & 0,5 & 11 & 1 & 17,6 & 5 \\
\hline GeoEye-1 & 2008 & USA & $0,4 / 1,6$ & 11 & 4 & 15 & $2 \ldots 3$ \\
\hline WorldView-2 & 2009 & USA & $0,46 / 1,84$ & 11 & 8 & 16 & 5 \\
\hline Cartosat-2B & 2010 & India & 0,8 & 10 & 1 & 9,6 & N/A \\
\hline Pleiades-1A & 2011 & France & $0,5 / 2$ & 12 & 4 & 20 & 4.5 \\
\hline Kompsat-3 & 2012 & Korea & $0,5 / 2$ & 14 & 4 & 17 & 13 \\
\hline Pleiades-1B & 2012 & France & $0,5 / 2$ & 12 & 4 & 20 & 4.5 \\
\hline SkySat-1 & 2013 & USA & $0,8 / 2,0$ & 11 & 4 & 8 & $\mathrm{~N} / \mathrm{A}$ \\
\hline Gaofen-2 & 2014 & China & $0,8 / 3,24$ & 10 & 4 & 45 & 50 \\
\hline ASNARO-1 & 2014 & Japan & $0,5 / 2,0$ & 11 & 6 & 10 & 10 \\
\hline WorldView-3 & 2014 & USA & $0,3 / 1,2$ & $11 / 14$ & 8 & 13 & 3.5 \\
\hline SkySat-2 & 2014 & USA & $0,8 / 2,0$ & 11 & 4 & 8 & $\mathrm{~N} / \mathrm{A}$ \\
\hline Kompsat-3A & 2015 & Korea & $0,4 / 1,6$ & 14 & 4 & 12 & 13 \\
\hline PeruSat-1 & 2016 & Peru & $0,7 / 2,0$ & 12 & 4 & 10 & N/A \\
\hline SkySat-3...7 & 2016 & USA & $0,8 / 2,0$ & 11 & 4 & 8 & N/A \\
\hline Gokturk-1A & 2016 & Turkey & $0,7 / 2,8$ & 12 & 4 & 20 & 10 \\
\hline $\begin{array}{c}\text { SuperView- } \\
1 \mathrm{~A} / \mathrm{B}\end{array}$ & 2016 & China & $0,5 / 2$ & 11 & 4 & 12 & 20 \\
\hline WorldView-4 & 2016 & USA & $0,3 / 1,2$ & 11 & 4 & 13 & 3 \\
\hline $\begin{array}{l}\text { Mohammed- } \\
\text { VIA }\end{array}$ & 2017 & Morocco & $0,7 / 2,8$ & 12 & 4 & 20 & N/A \\
\hline SkySat-8...13 & 2017 & USA & $0,8 / 2,0$ & 11 & 4 & 8 & N/A \\
\hline $\begin{array}{c}\text { SuperView- } \\
1 \mathrm{C} / \mathrm{D}\end{array}$ & 2018 & China & $0,5 / 2$ & 11 & 4 & 12 & 20 \\
\hline
\end{tabular}

* N/A - no information available

In order to detect changes in multidate satellite images of submeter spatial resolution, differential images are used wherein detecting changes by difference in values between adjacent pixels having the same geographical coordinates on two images reduced to the same spatial resolution. As a rule, panchromatic band data providing the highest granularity level and sensitivity are used. However, such a method has a significant disadvantage in its simplicity: it does not allow to detect changes in cases 
when compared objects have different level of brightness in multispectral bands, but similar in panchromatic band.

The research aims at improving the method for the automated detection of antropogenic changes in urban development with multispectral satellite producing sub-meter resolution imagery in the visible and infrared bands by combining the data of all spectral bands in order to increase the efficiency and reliability of urban map updating.

\section{Research methodology}

The territory of Healdsburg in Sonoma County, California, USA, was chosen as a test site to improve the method for the automated detection of antropogenic changes in urban development as there a rather high dynamics of urban in-frastructure development, including changes in housing and commercial facilities. Besides, the largest oil and gas pipelines are located in or near Healdsburg, which requires regular monitoring of changes in development in accordance with the existing standards. Multidate satellite images in visible and infrared bands acquired by Pleia-des-1A Satellite Sensor on May 31, 2012 and June 18, 2014 were selected for the analysis (Fig. 1).
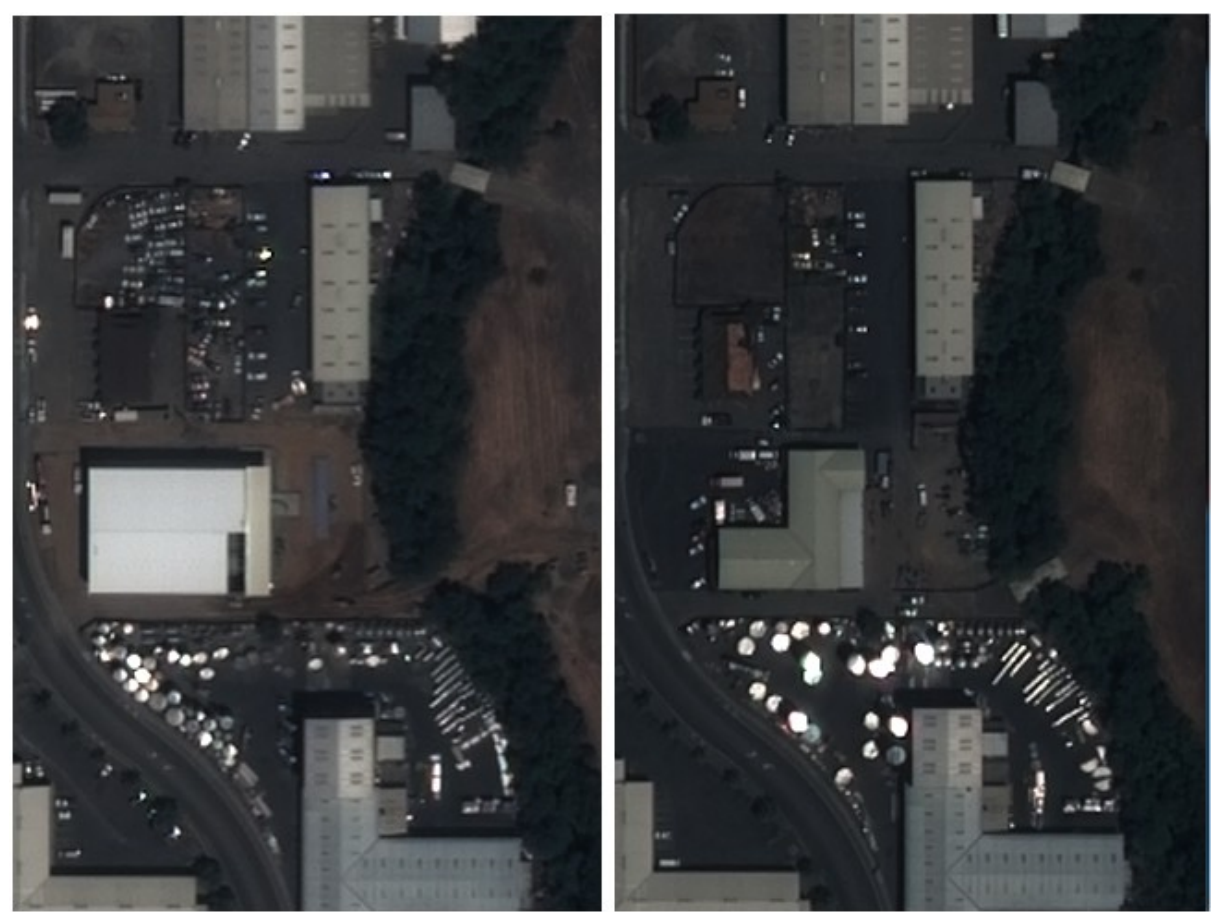

Fig. 1. Fragments of initial satellite images acquired on May 31, 2012 (left) and June 18, 2014 (right). 
The research comprised the following stages of image processing and analysis

- Pre-processing (normalization) of multidate satellite images, the same for the initial and the next images, including purification, augmentation of spatial resolution and correlative alignment to the reference image (Fig. 2);

- Thematic processing of normalized satellite images, including filtering of shadows and small mobile objects (cars, itinerant trade locations, etc.), calculation of the 1st principle component, two-threshold binarization, morphological and linear filtering and vectorization of identified changes (Fig. 3).

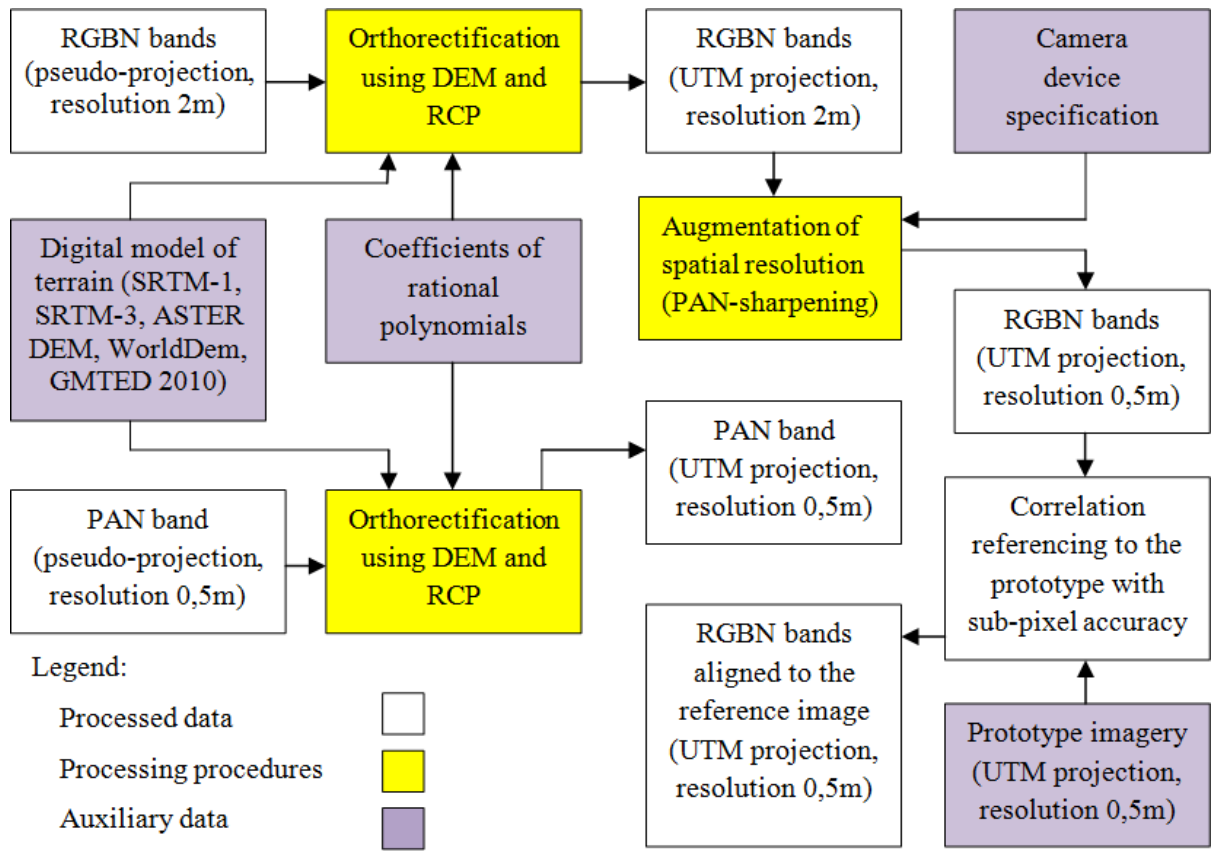

Fig. 2. The main stages of preliminary satellite images processing.

The most widely used methods for estimating the accuracy of satellite image change detection are [15]:

- comparing the results of automated remote sensing data classification with synchronous ground based observations and measurements performed simultaneously with satellite imagery (or with a small time interval);

- comparing the results of automated remote sensing data classification with the results obtained with certified satellite image processing software packages (but it is difficult or impossible to assess the accuracy of the standard measure); 
- comparing the results obtained with manual classification of changes using remote sensing data with the operators' results evaluated by the expert group (this method is used for relatively small amount of data or for a limited set of test areas to be evenly spread across the investigated territory).

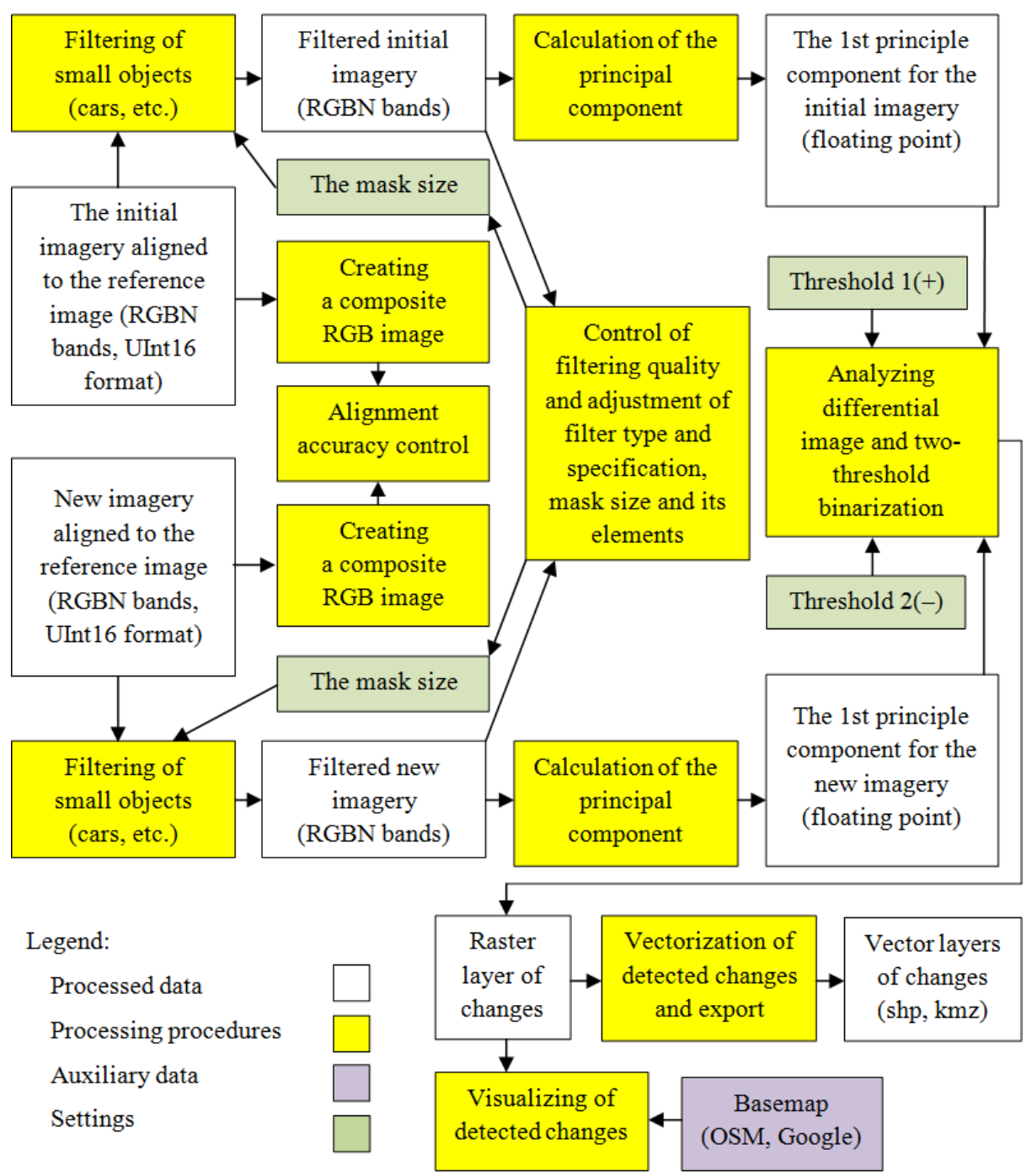

Fig. 3. The main stages of thematic satellite images processing.

Due to the lack of ground-based measurement data for the area under study, the last of the above mentioned methods was used to assess the accuracy of anthropogenic changes automated detection. Which means that comparison of the results obtained with manual classification of changes was performed for separate fragments of RGB 
image in interactive mode within the QGIS software environment. The expert assessment of the standard measure accuracy thus obtained averaged $5 \ldots 9 \%$.

\section{$3 \quad$ Results and discussion}

The file sizes of high-spatial resolution multi-spectrum images are usually large enough (for example, a scene imaged in the visible and IR range can take several gigabytes). Therefore, it is desirable to use modern computers with Intel Core i7 processors or higher and at least $64 \mathrm{~GB}$ of RAM to quickly process real-time images taken by the SuperView 1A. The software can be either commercial (ERDAS, ENVI, ArcGIS, etc.) or free (SNAP, SAGA, GRAAS, QGIS, etc.), run in both MS Windows and Linux environments. To provide more efficient automation of processing procedures it is possible to use tools (e.g. Imagine Model Maker in ERDAS package, Graph Builder in SNAP package) or programming languages and specialized utilities (e.g. IDL in ENVI package, Python GDAL in QGIS system).

A differential image was obtained after normalization and filtering of multispectration satellite images in visible and IR ranges acquired by the Pleiades-1 A sensor on May 31, 2012 and June 18, 2014. It was further used to determine changes in urban development (Fig. 4).

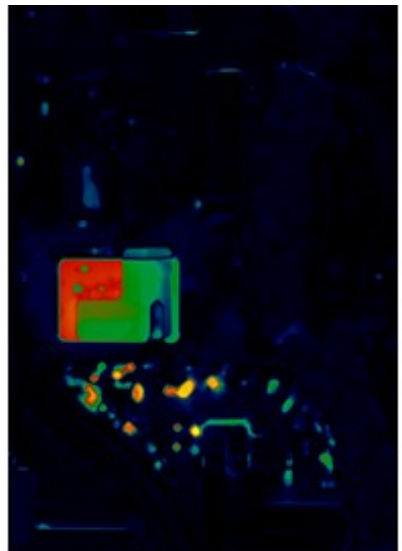

Detected changes

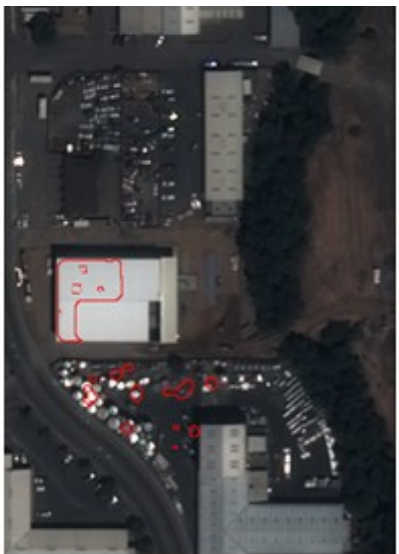

Vector + initial image

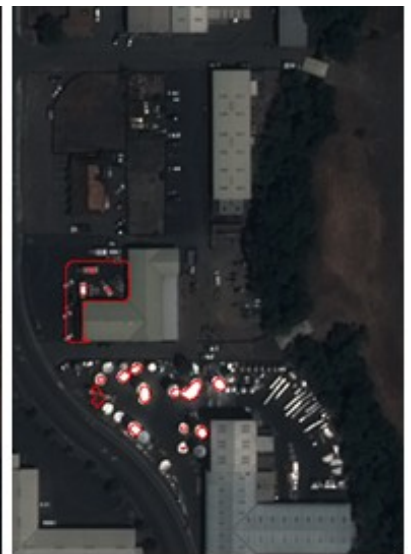

Vector + next image

Fig. 4. Detected changes and vector layers overlay on a raster.

The boundaries of the detected building changes were sufficiently accurately identified on various test areas. The high level of the proposed method stability was confirmed without using additional vegetation and water masks.

The main advantages of the proposed method in comparison with those using only panchromatic band data are the ability to detect changes in cases when initial and next images of the objects being analyzed have the same albedo values in the panchromatic band. This contributes to significant improvement of change detection accuracy. 
Besides, due to the high degree of satellite image processing automation, the methodology can significantly reduce complexity and thus increase the operational efficiency of map updating. The software implementation of this methodology in the form of a geo-information web service, compared to traditional software and hardware, has significant organizational, technical and economic advantages, such as:

- it works directly in the browser, which does not require installation of additional software;

- $\quad$ software and hardware independence, which ensures using this web service on mobile devices;

- the results of image processing are stored on the server, which allows all customers to use the web service regardless of their location;

- high economic efficiency (does not require purchase of powerful graphic stations and expensive software);

- $\quad$ minimum requirements for the end-user training (there is no need to spend time studying large and complex software packages).

The practical application of the proposed method is quite extensive as it provides automated detection of changes not only in urban development, but also in any other natural and man-made objects (road network, plant and water objects, etc.). Therefore it could be used for the benefit of various State services, private companies and commercial entities. With software implementation of this methodology in the form of a geo-information web service, it can be used for informing the mass user - population.

The results of this research are included in the educational materials for lectures and laboratory classes being a part of the module "Ultra-high spatial resolution satellite images processing" for senior students of the Dnepropetrovsk National University named after Oles' Honchar within the framework of the course "Remote sensing systems" and also used to prepare course and diploma papers. Students test the proposed methodology experimentally using multispectral images of various Earth areas acquired by the existing RSS satellites.

\section{Conclusion}

An efficient method for the automated detection of antropogenic changes in urban development with multispectral satellite producing sub-meter resolution imagery in visible and IR-bands is proposed. It significantly reduces complexity and thus increases operational efficiency and accuracy of map updating due to automation of satellite imagery processing and can be used to solve various applied tasks that are associated with construction, communication lines, engineering communications, etc.

Directions of further research. Currently, the proposed methodology is being developed using multispectral images of different Earth areas acquired by the existing submeter resolution satellites in order to determine the optimal operation parameters for the main types of modern on-board sensors taking into account the environmental and imaging conditions. In addition, this method is being improved with regard to the use of additional vegetation and water masks in order to enhance stability and quality of detection. 


\section{Acknowledgments}

This work was supported by the Ministry of Education and Science of the Russian Federation in the framework of the Federal target program «Research and development of priority directions of development of the scientific-technological complex of Russia for 2014-2020» (unique ID project RFMEFI60519X0185).

\section{References}

1. Lu, D., Li, G., Moran, E.: Current situation and needs of change detection techniques. International. Journal of Image and Data Fusion 5, 13-38 (2014).

2. Tewkesbury, A., Comber, A., Tate, N., Lamb, A., Fisher, P.: A critical synthesis of remotely sensed optical image change detection techniques. Remote Sensing of Environment 160, 1-14 (2015).

3. Aleksandrowicz, S., Turlej, K., Lewiński, S., Bochenek, Z.: Change detection algorithm for the production of land cover change maps over the European union countries. Remote Sensing 6, 5976-5994 (2014).

4. Tian, J., Chaabouni-Chouayakh, H., Reinartz, P., Krauss, T., D’Angelo, P.: Automatic 3D change detection based on optical satellite stereo imagery. In: ISPRS Technical Commission VII Symposium on Advancing Remote Sensing Science, vol. 38, pp. 586-591. ISPRS, Vienna, Austria (2010).

5. Rottensteiner, F.: Automated updating of building databases from digital surface models and multi-spectral images. In: The International Archives of the Photogrammetry, Remote Sensing and Spatial Information Sciences, vol. XXXVII, part B3a, pp. 265-270. Beijing, China (2008).

6. Deng, J., Wang, K., Deng, Y., Qi, J.: PCA-based land-use change detection and analysis using multitemporal and multisensor satellite data. Int. J. Remote Sens. 29, 4823-4838 (2018).

7. Champion, N., Boldo, D., Pierrot-Deseilligny, M., Stamon, G.: 2D building change detection from high resolution satellite imagery: A two-step hierarchical method based on 3D invariant primitives. Pattern Recognition Letters 31, 1138-1147 (2010).

8. Le Bris, A., Chehata, N.: Change detection in a topographic building database using submetric satellite images. In: International Archives of Photogrammetry, Remote Sensing and Spatial Information Sciences, vol. 38(3/W22), pp. 25-30. ISPRS, Munich, Germany (2011).

9. Malpica, J., Alonso, M.: Urban changes with satellite imagery and LiDAR data. In: International Archives of the Photogrammetry, Remote Sensing and Spatial Information Sciences - ISPRS Archives, vol. 38, pp. 853-858. ISPRS, Kyoto, Japan (2010).

10. Awrangjeb, M., Zhang, C., Fraser, C.S.: Improved Building Detection Using Texture Information. In: International Archives of the Photogrammetry, Remote Sensing and Spatial Information Sciences - ISPRS Archives, vol. 38 (3W22), pp. 143-147. ISPRS, Munich, Germany, (2011).

11. Bouziani, M., Go"ita, K., He, D.-C.: Automatic change detection of buildings in urban environment from very high spatial resolution images using existing geodatabase and prior knowledge. ISPRS Journal of Photogrammetry and Remote Sensing 65, 143-153 (2010). 
12. Matikainen, L., Hyyppa, J., Ahokas, E., Markelin, L., Kaartinen, H.: Automatic detection of buildings and changes in buildings for updating of maps. Remote Sensing 2(5), $1217-$ 1248 (2010).

13. Dini, G.R., Jacobsen, K., Rottensteiner, F., Al Rajhi, M., Heipke, C.: 3D Building Change Detection Using High Resolution Stereo Images and a GIS Database. In: International Archives of the Photogrammetry, Remote Sensing and Spatial Information Sciences - ISPRS Archives, vol. 39, pp. 299-304. ISPRS, Melbourne, Australia (2012).

14. Mozgovoy, D.K., Hnatushenko, V.V., Vasyliev, V.V.: Automated recognition of vegetation and water bodies on the territory of megacities in satellite images of visible and IR bands. ISPRS Annals of the Photogrammetry, Remote Sensing and Spatial Information Sciences, vol. 4(3), pp. 167-172. Beijing, China, 2018.

15. Mozgovoy, D., Hnatushenko, V., Vasyliev, V.: Accuracy evaluation of automated object recognition using multispectral aerial images and neural network. In: Proceedings of SPIE - The International Society for Optical Engineering, vol. 10806, art. 108060H. SPIE, Shanghai, China (2018). 